\title{
Reading Speed Improvement in a Speed Reading Course and Its Effect on Language Memory Span
}

\author{
Thi Ngoc Yen Tran \\ (ngocyenkitty@gmail.com) \\ Vinh University, Vietnam \\ Paul Nation \\ (Paul.Nation@victoria.ac.nz) \\ Victoria University of Wellington, New Zealand
}

\begin{abstract}
Several studies have shown positive effects of a speed reading course on students' reading speed improvement (Chung \& Nation, 2006; Macalister, 2008, 2010). Yet, little research has aimed to see if the speed increase transfers to other types of reading and if it has any effects on other language skills. This study set out to answer these questions and examine the relationships between EFL reading speed, reading comprehension, and memory span by looking at the comprehension scores and language memory span results. It was found that the reading speed improvement in the speed reading course transferred to other types of reading and did not necessarily negatively affect comprehension. The results demonstrated that the treatment groups considerably expanded their memory span $(\mathrm{p}<.05)$. Strong relationships between speed increases in the speed reading course, speed improvement in other types of reading and memory span development were also found.
\end{abstract}

\section{Introduction}

Reading fluency has a long history in first language acquisition, but has only become an area of research interest in second language learning in the last few decades. Recent studies in English as a foreign language (EFL) reading fluency have looked at methods to increase reading speed and ways to assess reading fluency. Yet questions have been raised about the optimal results of speed improvement and whether reading instructors should encourage learners to try to improve their reading rates, as an increase in reading rate may result in a decrease in reading comprehension (Carver, 1992). The objectives of this study are to determine the relationship between reading speed improvement and comprehension, and examine the effects of EFL reading speed development on language memory span. The answer to the first issue will enhance our understanding of the speed-comprehension relationship and may thus be helpful for reading instructors who are hesitating to use methods to help their learners increase their reading rate. The answer to the latter issue will add to a growing body of literature on further impacts of reading speed improvement.

This paper consists of four sections. The first section gives a review of the recent research of reading speed, reading comprehension, language memory span, and speed reading courses. The second section describes the research methodology, including information about participants, materials, and procedures. The third section provides the results of reading speed improvement through the speed 
reading course, speed transfer to other types of reading, and language memory span development. The last section presents discussions on the findings and implications for future practice and research.

\section{Literature review}

\subsection{Reading speed and reading comprehension}

While reading speed is generally thought to be associated with reading comprehension and past research has given insight into the relationship between these aspects, there has still been much controversy on this issue. A strong relationship between reading rate and comprehension in L1 reading has been reported in previous studies (Bowey, 2005; Fuchs, Fuchs, Hosp, \& Jenkins, 2001; Perfetti, Landi, \& Oakhill, 2005). Specifically, Nicholson and Tan (1997) and Levy, Abello and Kysynchuk (1997) found that poor readers benefit from rapid decoding training and suggested that, in L1 children's oral reading, speed increases facilitate comprehension (Nicholson \& Tan, 1999). However, other researchers have demonstrated a weak relationship between fluency skills and reading comprehension level (Bell, 2001; Kuhn \& Stahl, 2003; Schwanenflugel et al., 2006).

The link between comprehension and speed in second/foreign language (L2/FL) reading has not been clearly portrayed. Past research found that speed and comprehension are not competing components in L2 performance, and that the two factors have a supporting relationship in that speed promotes accuracy in comprehension and accuracy is one of the indicators of fluency development (Alessi \& Dwyer, 2008). In Chang's (2010) study, a reading activity was integrated into the usual program for 13 weeks to improve 84 college students' reading rates. Results indicated that the participants increased their reading speed by $25 \%$ and their comprehension level increased by $4 \%$. This low increase is probably due to a ceiling effect in the measurement, but it shows that speed increase does not result in a drop in comprehension.

Since a consensus on the association between speed and comprehension in both first language (L1) and L2/FL reading has not been established, it would be helpful to put some effort into investigating the relationship between speed and comprehension in L2/FL reading by looking at the comprehension scores on other types of reading to determine if reading speed improvement facilitates comprehension.

\subsection{Memory span}

Past research in reading has primarily looked at working memory span, which is a common measure of short-term memory (Fortkamp, 1999; Kormos \& Sáfár, 2008; Weissheimer \& Mailce, 2009). While short-term memory is thought of as a passive storage buffer, working memory span is widely defined as the mental capacity available for the simultaneous processing and storage of information, and thus a more active part of the human processing system (Daneman \& Carpenter, 1980; Just \& Carpenter, 1992). Specifically in reading, the reader's working memory stores syntactic, semantic, pragmatic information from the preceding text for later use. Because information can be lost from working memory through decay or displacement, there is a trade-off relationship between processing and storage in reading comprehension and this can be a source of individual differences in reading comprehension (Daneman \& Carpenter, 1980).

Past research has found a causal link between working memory span and L1 reading ability, naming rate, and speech rate. This suggests that memory span, naming rate and speech rate are in a linear function to reading ability and good readers do better in all three tests than poor readers (Das \& Mishra, 1991). Researchers also found a strong relationship between working memory span and L2 performance (Fortkamp, 1999; Harrington \& Sawyer, 1992; Kormos \& Sáfár, 2008; Weissheimer \& Mailce, 2009).

While reading research commonly uses reading span tasks and working memory span tasks to measure working memory, a few researchers have also attempted to use sentence memory span 
tests, which is also called language memory span tests in order to predict learners' language proficiency. Harris (1970), for example, developed a language memory test which consisted of a series of phrases or sentences of increasing length and syntactical complexity for oral repetition. He reported that the results of this sentence memory span test correlated with the results of English language proficiency tests. Roberts and Gibson (2002) utilised a sentence memory test which required the participants to listen to sentences containing one, two, three, four and five clauses and then answer questions about the sentence content. Although they found that the results of this test significantly correlated with the results of a reading span test, they suggested that memory for sentences is not necessarily a result of linguistic experience, but rather a contribution of an independent working memory component. Seung and Chapman (2004), using an auditory sentence memory span measure carried out in connection with a speaking rate test, demonstrated that language production level accounted for a substantial portion of individual differences in sentence memory span.

In this study, the sentence memory span tests did not require the participants to store or remember information, while other processes were occurring. The participants only had to remember each sentence and write it down without having to engage in any other process. They could choose when to proceed with the next sentence, once they had finished. Unlike the other sentence memory span tests, the sentence memory span tests used in this study were not done orally. Instead, the participants were allowed to read the sentences appearing on the computer screen before typing them onto the computer. This was done for several reasons. First, if the tests had required the participants to listen to the sentences and then write them down, it would have been difficult to decide if a mistake was made due to faulty listening or faulty memory span, because the participants were not native speakers of English. Second, because the treatment was done in reading, it would be more relevant to let the participants read rather than listen to the sentences in the tests. Third, if the participants had been asked to repeat the sentences orally, it would have been hard to decide if a mistake was caused by faulty memory span or faulty pronunciation.

\subsection{Speed reading courses}

There has been a growing body of literature on timed reading or speed reading as one of the methods to increase L2/FL reading speed (Chung \& Nation, 2006; Fry, 1967; Hunter, 1975; Macalister, 2008, 2010; Quinn \& Nation, 1974). A course of this kind usually consists of around 20 texts of equal length and difficulty level, each accompanied by comprehension questions. During the course, the students read the texts and keep a record of their reading rate and comprehension scores. Although little research has explored the effects of reading speed improvement on other languages besides English, a few studies have found that speed reading courses were effective in helping learners to increase their reading rates (Bismoko \& Nation, 1972; Cramer, 1975; Chung \& Nation, 2006; Macalister, 2008, 2010). Macalister (2010) found some evidence of speed increases in speed reading courses transferring to reading outside the course.

In conclusion, there is evidence that during a speed reading course, L2 learners can improve their reading rate, but stronger evidence is needed on whether that improvement transfers to other types of reading and affects other language skills. This study, thus, aimed to measure the effects of speed reading courses on reading rate improvement both in and outside the courses and the effects of the speed improvement on language memory span.

The research addresses the following questions:

1. Will the speed improvement in the speed reading course transfer to other types of reading?

2. Will reading speed improvement contribute to learners' development of language memory span? 


\section{Methodology}

\subsection{Materials}

The book "Asian and Pacific Speed Readings for ESL Learners" by Millett, Quinn and Nation (2007), an adapted version of Quinn and Nation (1974), was used for the speed reading course. This book contains twenty 550 -word passages written at the 1000 word level. Each of the texts was accompanied by ten comprehension questions. It was shown in the pilot tests that all the texts were roughly equal in terms of difficulty level and were relevant for learners who have reached the $2^{\text {nd }} 1000$ word level.

In order to make sure that the participants had reached the desired vocabulary level for the speeding reading course, they sat a vocabulary test. The test was taken from Schmitt, Schmitt and Clapham (2001).

The two texts used for the pre-test and post-test were taken from graded readers at the 1000 word level but modified to contain similar numbers of total words, academic words, words at the 1000 word level, words at the 2000 word level, and off-list words. Each of the texts was accompanied by ten comprehension questions and was then put in a computer program. These texts were longer and involved different topics from the twenty texts in the course. They were read on a computer screen rather than in hard copy so that the administrator did not have to control the starting time of all the participants. The program automatically recorded the time when the participants clicked the "Next" button to see the comprehension questions. The researcher did not have to count the number of words that each participant read in one minute, as the computer program did it automatically.

To determine whether speed increases in the course were accompanied by language memory span improvement, two memory span sets were utilized for the pre-test and post-test. Each memory span set consisted of 20 sentences that were written within the 1000 word level. The sentences were of increasing length and syntactical complexity. The two sets contained corresponding sentences that were equal in terms of vocabulary level, length, and grammatical difficulty. In the present experiment, the sentences were part of a computer program, which allowed the participants to read each of the sentences within a certain amount of time, and then write it from memory.

Pilot testing was done on the twenty texts in the speed reading book, the vocabulary test, the pre-test and post-test texts, the memory language span sets of sentences and the language memory span computer program. Some changes were made upon the first pilot testing results and the second pilot testing showed that no texts in the speed reading book were markedly easier or more difficult than the others, the vocabulary test worked well, the pre-test and post-test texts and test instructions accompanying them were comprehensible, the sentences in the two memory span sets were equal in terms of difficulty, and the computer program worked smoothly.

\subsection{Participants}

The study involved 116 first-year students at a university in Vietnam. They were put into four groups: two experimental groups, hereafter called Group A (31 students) and Group B (30 students), and two control groups, hereafter called Group C (26 students) and Group D (29 students). The participants in Groups A, B and C were English majors at the university. The participants in Group D were non-English majors. The following criteria were applied when choosing participants for Group D in order to equalize participants in this group with participants in the other groups: First, their age range was from 19 to 23. Second, they had been studying English for the same length of time as the other participants had. Third, their background education was similar to that of the other groups. Fourth, they did not follow the English program that the other participants did, but they followed a general English course, which lasted for the same length of time.

A brief description of the treatment and variables that the four groups followed is presented in Table 1. 
Table 1. Brief description of what the four groups followed during the experiment

\begin{tabular}{ccccc}
\hline $\begin{array}{c}\text { Group } \\
\text { name }\end{array}$ & $\begin{array}{c}\text { Number of } \\
\text { participants }\end{array}$ & Speed reading course & $\begin{array}{c}\text { Usual English } \\
\text { program }\end{array}$ & $\begin{array}{c}\text { English course at the } \\
\text { language centre }\end{array}$ \\
\hline A & 31 & YES & YES & NO \\
B & 30 & YES & YES & NO \\
C & 26 & NO & YES & NO \\
D & 29 & NO & NO & YES \\
\hline
\end{tabular}

\subsection{Procedures}

Before the treatment started, all participants in the four groups sat the pre-test on reading other types of texts and memory span. After that, the treatment groups (Group A and Group B) followed both the speed reading course and the usual English program. The control groups did not follow the speed reading course, but one of them (Group C) followed the usual English program at the university and the other (Group D) attended an English course at a language centre. The usual English program at university and the English course at the language centre both lasted for 15 weeks.

At the beginning of the speed reading course, the two treatment groups took the vocabulary test and it was shown that all the participants had reached the $2^{\text {nd }} 1000$ word level. In each of the speed reading sessions, the texts were distributed among the participants in the way that as few students as possible were reading the same passage at the same time. This was to control the possibility of different difficulty levels between the passages.

The speed reading program lasted for ten weeks with two sessions per week and involved each learner choosing a passage to read, waiting for the teacher to tell them when to start, doing the reading, noting the time taken to read the passage, answering the ten multiple-choice questions without looking at the text again, marking their answers using an answer key, converting their reading time into words per minute, and entering their speed and comprehension scores onto a graph.

When the speed reading course, the usual English program, and the general English course at the centre ended, the four groups sat the post-tests on reading other types of texts and memory span test. In order to eliminate the text effect, for the pre-test, half of the participants from each group read one text and the other half read the other text. For the post-tests, the administration of the texts was the reverse of that for the pre-tests.

\section{Results}

\subsection{Speed increases in the speed reading course}

The participants' speed increases were measured using four different scoring methods. Three of those methods were used by Chung and Nation (2006): The average scoring method takes the average score of the first three texts minus the average score of the last three texts; the $20^{\text {th }}$ minus $1^{\text {st }}$ scoring method takes the score of the $20^{\text {th }}$ text minus the score of the $1^{\text {st }}$ text; the extreme scoring method takes the highest score minus the lowest score. The fourth method, called the three extremes scoring method, was formulated while we were analysing the data. This method takes the average score in the best three sessions minus the average score in the worst three sessions.

Similar rankings for the two treatment groups were found using the four different scoring methods. Both groups made average increases of at least $50 \mathrm{wpm}$ using each method (see Table 2). The reliability of the speed improvement both groups made was reinforced by the fact that the two groups had similar average initial scores, thus demonstrating that the four scoring methods agree with each other.

It was also found that most of the participants had their slowest speed in the first half and their fastest speed in the second half of the course, and that most of the participants continued to in- 
crease their speed after the $10^{\text {th }}$ session and many kept improving during the last five sessions (see Table 3). These facts show that the participants made a real improvement and the speed reading course was bringing about continual improvement.

Table 2. Means and standard deviations of in-course reading speed increases for the treatment groups

\begin{tabular}{llcc}
\hline Measure & & Group A & Group B \\
\hline \multirow{2}{*}{ Average method } & Mean & 57.00 & 50.90 \\
& SD & 40.52 & 29.91 \\
\hline \multirow{2}{*}{$20^{\text {th }}$ minus $1^{\text {st }}$ method } & Mean & 61.03 & 51.03 \\
& SD & 48.14 & 38.44 \\
\hline \multirow{2}{*}{ Three extremes method } & Mean & 80.38 & 73.16 \\
& SD & 32.99 & 30.62 \\
\hline \multirow{2}{*}{ Extreme method } & Mean & 97.67 & 87.83 \\
& SD & 45.10 & 36.43 \\
\hline
\end{tabular}

Table 3. The percentage of participants having their slowest and fastest speeds in the four phases of the course

\begin{tabular}{lcccc}
\hline Passages & \#1 to $\# \mathbf{5}$ & \#6 to \#10 & \#11 to $\# \mathbf{1 5}$ & \#16 to \#20 \\
\hline Slowest speed & $89 \%$ & $11 \%$ & $0 \%$ & $0 \%$ \\
Fastest speed & $3 \%$ & $7 \%$ & $20 \%$ & $70 \%$ \\
\hline Three slowest speeds & $83 \%$ & $14 \%$ & $3 \%$ & $0 \%$ \\
Three fastest speeds & $2 \%$ & $8 \%$ & $18 \%$ & $72 \%$ \\
\hline
\end{tabular}

In each of the sessions, after reading the text, the participants had to answer ten comprehension questions, and their comprehension accuracy was measured by counting the number of correct answers they made for each of the twenty texts in the course. Not only was the average score for the first three texts compared with the average score for the last three texts, but also the average score of the first half of the course was compared with the average score of the second half of the course.

The results, as shown in Table 4, indicate that both groups made slight increases in the average score of the last three sessions compared with the average of the first three sessions. The same trend was shown when comparing their average scores of the first half of the course with their average scores of the second half of the course. Besides, the small standard deviations indicate that comprehension was generally around the desired 7 out of 10 . It can be concluded that most participants can keep their comprehension accuracy, as they increase their reading speed. This reinforces the idea that they make progress in reading speed and that speed reading courses help readers improve their speed without compromising their comprehension. Because there were ten comprehension questions for each text and they focused largely on global comprehension, a ceiling effect was operating on the scores allowing only small increases.

Table 4. Means and standard deviations of comprehension scores of the first three texts, the last three texts, texts in the first half and the second half of the course for the two treatment groups

\begin{tabular}{llcc}
\hline Measure & & Group A & Group B \\
\hline \multirow{2}{*}{ First three texts } & Mean & 7.34 & 7.16 \\
& SD & 0.85 & 0.59 \\
\hline \multirow{2}{*}{ Last three texts } & Mean & 7.84 & 7.74 \\
& SD & 0.68 & 0.65 \\
\hline \multirow{2}{*}{ First half of the course } & Mean & 7.11 & 7.21 \\
& SD & 0.58 & 0.37 \\
\hline \multirow{2}{*}{ Second half of the course } & Mean & 7.67 & 7.44 \\
& SD & 0.45 & 0.31 \\
\hline
\end{tabular}




\subsection{Speed increase transfer from the speed reading course to other types of reading}

The data from the pre-test and post-test on reading other texts that were not in the speed reading course were analyzed to see if the participants' speed increases transferred from the course to other types of reading.

Table 5. Mean speed increases and standard deviations on other types of reading for all groups

\begin{tabular}{llcccc}
\hline & & \multicolumn{2}{c}{ Treatment groups } & \multicolumn{2}{c}{ Control groups } \\
\cline { 3 - 6 } & & Group A & Group B & Group C & Group D \\
\hline \multirow{2}{*}{ Individual groups } & Mean increase & 46.16 & 50.43 & 10.46 & 19.65 \\
& SD & 27.34 & 24.28 & 29.60 & 27.37 \\
\hline Average of two treatment & Mean increase & \multicolumn{2}{c}{48.26} & \multicolumn{2}{c}{15.30} \\
groups and two control groups & SD & \multicolumn{2}{c}{25.76} & \multicolumn{2}{c}{28.56} \\
\hline
\end{tabular}

As can be seen from Table 5, while the control groups' average increase was only $15 \mathrm{wpm}$, the treatment groups' average increase was over three times bigger (48 wpm). A one way ANOVA showed that the mean scores of the four groups were significantly different, $F(3,90)=16.78, \mathrm{p}$ $<.001$. Tukey post hoc comparisons indicated that the treatment groups $\mathrm{A}(\mathrm{M}=46.16, \mathrm{SD}=27.34)$ and $\mathrm{B}(\mathrm{M}=50.43, \mathrm{SD}=24.28)$ both had a significantly $(\mathrm{p}<0.001)$ higher mean improvement than the control groups $\mathrm{C}(\mathrm{M}=10.46, \mathrm{SD}=29.60)$ and $\mathrm{D}(\mathrm{M}=19.65, \mathrm{SD}=27.37)$.

Since all groups started at similar speeds (see Table 6) but the treatment groups reached much higher speeds on the post-test, it can be assumed that most of the speed increases were an improvement as a result of the speed reading course not of calculation methods or unequal initial speeds. The data also showed that the participants who read Text A for the pre-test and Text B for the post-test and the participants who read them the other way round made similar average increases, thus suggesting that the difficulty of the texts themselves was not the cause of pre-test and post-test differences.

Table 6. Means and standard deviations of initial speeds, final speeds and speed increases on other types of reading for all groups

\begin{tabular}{llcccc}
\hline & & \multicolumn{2}{c}{ Treatment groups } & \multicolumn{2}{c}{ Control groups } \\
\cline { 3 - 6 } & & Group A & Group B & Group C & Group D \\
\hline \multirow{2}{*}{ Pre-test } & Mean & 118.87 & 119.73 & 118.96 & 113.82 \\
& SD & 34.95 & 39.61 & 26.11 & 30.72 \\
\hline \multirow{2}{*}{ Post-test } & Mean & 165.03 & 170.16 & 129.42 & 133.48 \\
& SD & 36.75 & 34.61 & 20.50 & 27.18 \\
\hline \multirow{2}{*}{ Increase } & Mean & 46.16 & 50.43 & 10.46 & 19.65 \\
& SD & 27.34 & 24.28 & 29.60 & 27.37 \\
\hline
\end{tabular}

Table 7. Means and standard deviations of initial comprehension scores (Initial CS), post-test comprehension scores (Final CS), initial speeds (IS) and final speeds (FS) for three subgroups

\begin{tabular}{|c|c|c|c|c|c|c|c|c|}
\hline Group & $n$ & & Initial CS & Final CS & Difference & IS & FS & Difference \\
\hline \multirow{2}{*}{$\begin{array}{l}\text { Increase } \\
\text { group }\end{array}$} & \multirow{2}{*}{72} & Mean & 4.81 & 7.36 & 2.56 & 116.42 & 160.28 & 43.86 \\
\hline & & SD & 1.73 & 0.91 & 1.73 & 33.75 & 36.52 & 27.39 \\
\hline \multirow{2}{*}{$\begin{array}{l}\text { Consistent } \\
\text { group }\end{array}$} & \multirow{2}{*}{24} & Mean & 6.67 & 6.67 & 0 & 129.58 & 138.67 & 9.09 \\
\hline & & SD & 1.81 & 1.81 & 0 & 33.37 & 29.72 & 25.82 \\
\hline $\begin{array}{l}\text { Decrease } \\
\text { group }\end{array}$ & 20 & Mean & 6.25 & 4.6 & -1.65 & 109.12 & $\begin{array}{l}131.09 \\
2571\end{array}$ & $\begin{array}{l}21.97 \\
22.63\end{array}$ \\
\hline
\end{tabular}

It can be seen from Table 7 that $62 \%$ of the participants increased their comprehension level (the increase group), $20 \%$ of them kept their comprehension at the same level (the consistent 
group) and only $17 \%$ had their comprehension scores decrease (the decrease group). The increase group was also the one which had the biggest increase in reading speed.

A comparison of the treatment groups' and the control groups' results shows that the treatment groups outperformed the control groups in comprehension (see Table 8). An analysis of the data at an individual level shows that only five participants among the 16 participants whose speeds decreased had a comprehension score increase and only 17 among the 100 participants whose speeds increased had a comprehension score drop. These results agree with the results drawn from the analysis at the group level. The findings suggest that the speed reading course helped the participants maintain their comprehension while increasing their reading speed. Thus, most of the participants who followed the course did not have to trade comprehension for speed. It might also be possible that there was a link between comprehension and reading speed improvement: the participants who greatly increased their speed tended to have improved their comprehension accuracy, while it was less likely that participants who only marginally increased their speeds would improve their comprehension accuracy.

Table 8. Comparison of comprehension improvement for the control groups and the treatment groups

\begin{tabular}{lcccc}
\hline & \multicolumn{2}{c}{ Treatment groups } & \multicolumn{2}{c}{ Control groups } \\
\cline { 2 - 5 } & Group A & Group B & Group C & Group D \\
\hline Increase group & $27(87 \%)$ & $26(87 \%)$ & $10(39 \%)$ & $9(31 \%)$ \\
Consistent group & $2(6 \%)$ & $2(7 \%)$ & $11(42 \%)$ & $9(31 \%)$ \\
Decrease group & $2(6 \%)$ & $2(7 \%)$ & $5(19 \%)$ & $11(38 \%)$ \\
\hline
\end{tabular}

\subsection{The effect of reading speed improvement on language memory span}

The participants sat a memory span test before and after the treatment. Each of the two memory span sets consisted of 20 sentences of increasing length and increasing complexity in grammar. The participants were allowed to see each of the sentences for a set time before they typed it onto the computer.

There were scoring criteria to make sure the results were reliable and systematic for the 116 participants. First, the test focused on receptive language rather than productive language. That is, we aimed to see how well the readers could cope with the sentences shown to them in terms of meaning, syntax and lexis. As a result, with regard to meaning, they were supposed to repeat the exact message of the sentences involved. Regarding syntax, they were supposed to provide the grammatically correct forms of the original sentences. In terms of lexis, they were supposed to repeat the same words and spelling as in the original sentences.

Generally, the errors made by the participants can be categorized into three groups: obvious spelling errors, grammatical errors and lexis errors. However, as the test was done on the computer, there were a number of errors where it was difficult to decide if they were caused by just a typing mistake or incorrect lexical knowledge and/or grammatical knowledge. Therefore, we also tried to analyze the data in other ways to compare the results between the pre-test and post-test for each individual. Table 9 summarizes the three scoring methods that were used.

The three scoring methods were named the tough method, the moderate method, and the generous method. For the tough method, no errors of any sort were accepted. For the moderate method, only obvious spelling mistakes were accepted. For the generous method, obvious spelling errors, grammatical errors and lexis errors were all accepted if they did not result in a meaning change. An example of a mistake resulting in a lexical meaning change is "She thought it was very interesting to listen to the talk about her brothers" instead of "She thought it was very interesting to listen to the talk about her friends." The generous method does not accept this mistake. An example of an error that does not result in a lexical meaning change is "Jack reads books in the library" instead of "Jack reads books at the library." The generous method accepts this mistake. 
Table 9. Scoring criteria for the language memory span tests

\begin{tabular}{lllll}
\hline Error type & & Tough & Moderate & Generous \\
\hline Spelling errors & & Not accepted & Accepted & Accepted \\
\multirow{2}{*}{$\begin{array}{l}\text { Grammatical } \\
\text { errors }\end{array}$} & $\begin{array}{l}\text { Errors resulting in } \\
\text { meaning change }\end{array}$ & Not accepted & Not accepted & Not accepted \\
\cline { 2 - 5 } & $\begin{array}{l}\text { Errors resulting in no } \\
\text { meaning change }\end{array}$ & Not accepted & Not accepted & Accepted \\
\hline \multirow{2}{*}{ Lexical errors } & $\begin{array}{l}\text { Errors resulting in } \\
\text { meaning change }\end{array}$ & Not accepted & Not accepted & Not accepted \\
\cline { 2 - 5 } & $\begin{array}{l}\text { Errors resulting in no } \\
\text { meaning change }\end{array}$ & Not accepted & Not accepted & Accepted \\
\hline
\end{tabular}

The participants' results for the pre-test and post-test were measured by counting the number of sentences correctly rewritten. The difference between the raw scores for the pre-test and posttest indicated the amount of improvement.

A preliminary analysis of the data using the tough method (see Table 10) indicated that the two treatment groups outperformed the two control groups in terms of average increases, the number of participants making an improvement and the number of participants not making any improvement.

Table 10. Increases in language memory span for all groups (tough scoring method)

\begin{tabular}{lccccc}
\hline & & Group A & Group B & Group D & Group C \\
\hline & Mean & 5.46 & 4.80 & 1.72 & 1.39 \\
Increases & SD & $(2.94)$ & $(2.68)$ & $(5.23)$ & $(4.00)$ \\
\hline $\mathrm{N}^{0}$ of participants with no improvement & & $2 / 31$ & $1 / 30$ & $12 / 29$ & $11 / 26$ \\
\hline $\mathrm{N}^{0}$ of participants with an improvement & & $29 / 31$ & $29 / 30$ & $17 / 29$ & $15 / 26$ \\
\hline $\mathrm{N}^{0}$ of participants with increases over 5.0 & & $17 / 31$ & $16 / 30$ & $9 / 29$ & $7 / 26$ \\
\hline
\end{tabular}

A repeated measures ANOVA was carried out on the pre-test (initial score) and post-test (final score) data. The repeated-measures factor was "time" (pre-test vs. post-test) and the betweensubjects factor was "group." The results are shown in Table 11.

Table 11. Means and standard deviations of pre-test and post-test memory span for all groups (tough scoring method)

\begin{tabular}{llccccccc}
\hline & & \multicolumn{4}{c}{ Groups } & \multicolumn{2}{c}{ Analysis of variance } \\
\cline { 3 - 8 } & & $A$ & $B$ & $C$ & $D$ & $\begin{array}{c}\text { Group } \\
\text { Time }\end{array}$ & Interaction \\
& & & & & & $F(3,112)$ & $F(1,112)$ & $F(3,112)$ \\
\hline Pre-test & Mean & 9.48 & 9.20 & 9.65 & 10.00 & & & \\
& SD & 3.30 & 3.09 & 3.21 & 4.04 & $2.96^{*}$ & $88.29^{* *}$ & $8.59^{* *}$ \\
\hline Post- & Mean & 14.94 & 14.00 & 11.04 & 11.72 & & & \\
test & SD & 2.56 & 2.84 & 3.19 & 3.08 & & & \\
\hline
\end{tabular}

$* * \mathrm{p}<.01, * \mathrm{p}<.05$

The results indicated that there was a general gain for all groups from pre-test to post-test, $\eta^{2}$ $=.441$. There was a great effect on the overall group, but it was not meaningful in the light of this research. The interaction (group $\mathrm{x}$ time) results showed that the memory span gains from pre-test to post-test for the two treatment groups were significantly greater than for the control groups, $\eta^{2}$ $=.187$. It can be clearly seen from Figure 1 that the treatment groups made significant gains in memory span, and their mean improvement was greater than the memory span gains of the control groups. 
In order to determine the nature of the interaction effect, a one way ANOVA was carried out to compare the gain scores (pre-test to post-test) of the four groups. The results showed the mean scores of the four groups were significantly different, $F(3,112)=8.59, \mathrm{p}=.000, \eta^{2}=.187$.

The mean gain score for Group A memory span development was $5.46(\mathrm{~N}=31, \mathrm{SD}=2.94)$. The mean gain score for Group B speed training was $4.80(\mathrm{~N}=30, \mathrm{SD}=2.68)$. The mean gain score for Group $\mathrm{C}$ was $1.39(\mathrm{~N}=26, \mathrm{SD}=4.00)$. The mean gain score for Group D was $1.72(\mathrm{~N}=29, \mathrm{SD}=$ $5.23)$.

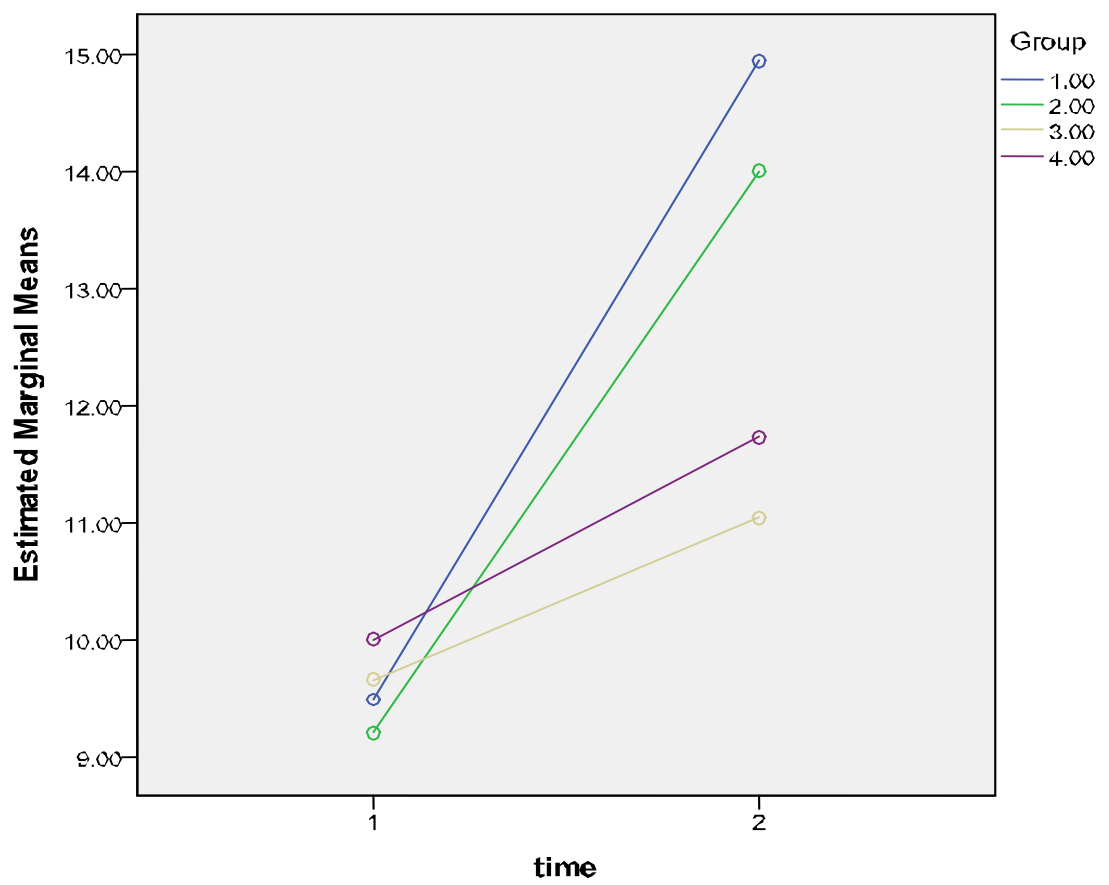

Fig. 1. Estimated marginal means of memory span increases for all groups

Pairwise comparisons using the Bonferroni adjustment for multiple comparisons showed a significant difference between Group A and Group C $(\mathrm{p}=.001)$ and between Group A and Group D. $(p=.002)$. There was also a significant difference between Group B and Group C $(p=.007)$ and between Group B and Group D $(\mathrm{p}=.015)$. There was no significant difference between Groups C and $\mathrm{D}(\mathrm{p}=1.000)$.

Analysis of the initial and final scores showed that in the pre-test the average scores of the treatment groups were slightly lower than the average scores of the control groups. The treatment groups' increases were a real improvement and not the result of the lower average scores at the beginning of the treatment. Further analysis indicated that in both pre-test and post-test, none of the participants had zero or 20, and that the participants who scored higher on the pre-test tended to score higher on the post-test, but the participants with shorter memory span could also increase it to a great degree to keep up with the participants who had already had a better memory span. These results demonstrated that there were no ceiling or floor effects, and that the difference between the participants' initial scores and final scores was real progress, not erratic behaviour. A comparison between the results by participants who had Set A and participants who had Set B in either pre-test or post-test indicated that there was no striking difference between the two groups. It can therefore be assumed that the different versions of language memory span did not distort the results.

A close link between the speed increases and increases in language memory span was also found. There was a trend that the greater the memory span increase one group made, the better 
reading speed improvement they achieved. In addition, the increases in memory span agreed very well with the increases in reading speed on other types of reading. The data indicated that the groups with better improvement in other types of reading also achieved greater increases in memory span.

An examination of the individual participants in each group (see Table 12) showed that the four groups had more participants reaching the more demanding parts of the post-test. The fact that the number of participants performing well on the easier parts did not noticeably change while the number of participants succeeding on the more demanding parts markedly increased showed that the participants had more correct answers and these answers were for sentences in the more difficult parts of the test. This suggested that the increases they made were a real improvement in memory span.

Table 12. Number of participants having correct answers in each part of the test for all groups

\begin{tabular}{cccccccccc}
\hline & \multicolumn{4}{c}{ Pre-test } & \multicolumn{4}{c}{ Post-test } \\
\hline & Group A & Group B & Group C & Group D & Group A & Group B & Group C & Group D \\
\hline Part 1 & 31 & 30 & 26 & 29 & 31 & 30 & 26 & 29 \\
Part 2 & 30 & 29 & 25 & 26 & 31 & 29 & 26 & 28 \\
Part 3 & 24 & 24 & 21 & 24 & 31 & 29 & 23 & 28 \\
Part 4 & 17 & 19 & 18 & 16 & 30 & 26 & 19 & 22 \\
Part 5 & 10 & 12 & 10 & 15 & 28 & 25 & 9 & 17 \\
\hline
\end{tabular}

The moderate method and the generous method were also used to count the scores gained by the participants and they produced similar results in terms of the ranking of the groups and the numbers of participants with no improvement and participants with improvement.

Taken as a whole, there was evidence that the treatment groups made more meaningful improvement in language memory span than the control groups, and the speed increases in the course facilitated language memory span development.

\section{Discussion}

\subsection{Reading speed improvement, reading comprehension in the course and speed increase transfer to other types of texts}

The study found that both treatment groups made increases over $50 \mathrm{wpm}$. This is a substantial improvement in reading speed and it is encouraging to reading instructors who are considering delivering a speed reading course to their learners. The results agree with Chung and Nation's (2006) findings about speed increase in the course and were reliable for the following reasons: First, the whole groups' results were not unduly affected by the individual results of the participants who increased their speed. Second, most of the participants had their slowest scores in the first half and highest scores in the second half of the course, and their increases followed a gradual pattern, showing that the progress occurred chronologically and their progress was caused by practice rather than some erratic behaviour or on-off effect. Third, the four scoring methods agreed with each other and produced the same ranking for the two treatment groups. Fourth, there was a relationship between the participants' initial speeds and their final speeds. More importantly, most participants were reading with $70 \%$ comprehension accuracy and could maintain this with a slight increase as they increased their reading speed, showing that they were reading and comprehending the text rather than just looking at the words without understanding them. This also demonstrates that, in a speed reading course in EFL, reading rate can increase without affecting comprehension.

The study's findings agree with Macalister's (2010) findings about speed increase transfer to other types of reading. It was found that both treatment groups substantially increased their speed on the texts that were not in the course and comparisons between the treatment groups and control groups were significant at the $\mathrm{p}<.05$ level. There were several other findings that reinforced the 
reliability of this result. First, the texts were confirmed to be equally difficult, thus producing no text effect. Second, all the groups had similar average speed on the pre-test, thus confirming that the treatment groups' increases were not caused by their initial speed being lower than the control groups'. Third, the initial speed was related to the final speed, and the in-course increases were related to the speed increases on other types of reading. These results indicated that the participants' increases were a real improvement rather than just some erratic or dishonest behaviour. Fourth, the participants' speed improvement was meaningful, because most of them had their comprehension accuracy increase or kept it at the same level, as they improved their reading rates.

On the question of fluency development and comprehension relationship, the study found that reading faster would not necessarily degrade comprehension and that the research participants could actually increase both reading rate and comprehension at the same time. More importantly, it was shown that the treatment groups made bigger increases in comprehension scores than the control groups. It must also be noted that a trade-off relationship between reading speed and comprehension level was found at the beginning of the treatment but not at the end of the treatment. These results corroborated the findings of a great deal of the previous work in this field (Chang, 2010; Fuchs et al., 2001; Stanovich, 2000) and reinforced the benefits of the speed reading course in that it helped the participants not only to improve their reading rates but also their comprehension.

\subsection{The effects of the speed reading course on language memory span}

In the present study, the participants' language memory span was assessed through the sentence memory span pre-test and post-test. Increasing reading fluency involves keeping larger stretches of language in mind while reading, so it is reasonable to expect a memory span increase. A set of criteria was established and three scoring methods were used to determine the participants' language memory span development. An analysis was also performed on the reliability and validity of the memory span sets. The results provided strong evidence that the two sets were equal enough to be interchangeably used for both the pre-test and post-test of memory span without causing any distorting data. The experiment therefore added to a growing but still small body of literature on assessing language memory span. Although there are second language studies of working memory span (Kormos \& Sáfár, 2008; Weissheimer \& Mailce, 2009), there are few that use second language sentences (Harris, 1970; Lado, 1965; Service, 1998).

The results indicated that the three scoring methods agreed with each other and produced the same ranking of the groups. It was found that the treatment groups outperformed the control groups. The data of the best scores, the worst scores, the most increases, the least progress, initial scores, final scores, the order of the sentences on which the participants provided correct answers, and the relationships between memory span increases and speed increases all supported the reliability of the result. First, the data indicated that there was no ceiling effect or floor effect. Second, the results of the participants who did Set A in the pre-test and Set B in the post-test were compared and it was found that there were no noticeable differences between the two categories. Third, the average initial scores demonstrated that the four groups had similar results in the pre-test, showing that their increases were not affected by their initial scores. Fourth, it was found that in the post-test, the participants could answer correctly more sentences in the more difficult parts of the test than in the pre-test. This showed that the increases made in the tests were a real improvement in memory span. Finally, yet importantly, the strong relationship between the increases in the course, the speed increases in other types of reading and the increases in memory span enhanced the idea that the memory span increases were a real improvement. Thus, it is likely that development in reading fluency facilitates development in language memory span. As the findings by Harris (1970), Roberts and Gibson (2002), and Seung and Chapman (2004) showed that a sentence memory span measure can indicate a learner's control of language complexity, it can be then hypothesized that development in reading fluency facilitates development in language complexity. This agrees with the findings by Yuan and Ellis (2003), who claimed that complexity develops, when fluency improves. However, more research on this topic needs to be undertaken, before the 
association between reading fluency development and language complexity development is more clearly understood.

The strong link between the three aspects, speed increases in the course, speed increases on other types of reading and memory span improvement, is one of the most interesting findings of the study. The data showed that the bigger the speed increases in the course and on other types of reading, the greater the improvement in memory span. This suggests that reading speed improvement not only transfers from speed reading to other types of reading, but is also accompanied by language memory span development. Several interpretations can be made of this result. First, the strong relationship among the increases in the three aspects reinforces the reliability of the study's results. It shows that the increases in any of these aspects were not distorted by some erratic or dishonest behaviour. Second, the trend that the participants with bigger increases in one aspect also made greater improvement in the other two aspects suggests that learners' improvement depends on some factors that are similarly effective for any aspects of language development; thus learners who have more of those factors will improve more in any of the three aspects. Some of those factors may be high motivation, good academic skills, positive learning attitudes, and confidence. However, in order to establish this, further research is required.

The experiment yielded some interesting data about language memory span and reading speed. In the first place, the same trend was found when comparing the individual participants' initial speeds with their final speeds and when comparing the participants' initial memory span with their final memory span. When putting all the participants in four groups together according to their initial speeds, it was found that the third best group could reach as high a speed as the second best group. Similarly, in memory span, the second best group could reach the same result as the best group and the fourth best group could reach as good a result as the third best group. These results suggest that the participants' reading speed improvement and memory span development do not depend on their starting levels. This is very encouraging for learners who are at lower levels of reading speed and memory span as it holds that through practice in the course, they can actually keep up with other learners who were initially better. Another interesting finding to emerge from the present experiment is that there was no connection between memory span and reading speed, even though the increases in these two aspects are strongly related. That is, the increase in reading speed predicts the amount of improvement in memory span, but a participant's reading speed does not predict their level of memory span. If we rank the participants according to their memory span, it does not agree with the ranking of their reading speeds. To generalize, it can be hypothesised that language memory span and reading speed concurrently develop, but are not a good predictor of each other. However, the relationship between reading speed and memory span is an intriguing one and further studies need to be done to explore the role of memory span in the reading process, to what extent it facilitates reading rate, if it does, and how it really affects and reflects the development of reading speed and other language aspects.

\subsection{Implications}

The study has several implications for practice and research. In the first place, it was found that reading speed development does not necessarily happen with a trade off in comprehension. In contrast, comprehension can be maintained or improved along with reading speed improvement. The results indicated that participants who had not been trained with speed reading tended to slow down their speed, when they wanted to obtain better comprehension. As a result, their reading rate and comprehension appeared to be in a trade-off relationship. However, after being trained in speed reading, they could increase their reading speed without their comprehension declining. Many of them even improved their comprehension scores while increasing their reading rate. This finding may be helpful for teachers and learners, as it encourages learners to read faster without having to fear that they will comprehend less. For a long time, reading instructors have struggled with the learners' low confidence about their comprehension level, which probably creates a psychological barrier in the learning process. Thus, evidence that comprehension and reading speed 
are not in a trade-off relationship may help teachers and learners to be more confident to use techniques and devices to promote reading speed.

Secondly, the results demonstrated that improvement in reading rate promotes language memory span. It was found that reading speed increases and memory span increases are highly related. The greater the improvement in reading rate, the bigger the increase in memory span. On the other hand, it was surprising that memory span and reading speed are not good predictors of each other. In other words, knowing individual learners' memory span does not help predict their reading rate and vice versa. These findings are consistent with those by Das and Mishra (1991), which indicated that good readers did better in memory span tests than poor readers, but prediction of reading rate from memory span was weak. A pedagogical implication of these findings is that syllabus designers should take advantage of fluency-oriented components, as development of speed can facilitate language memory span. It is also worth noting that further research needs to explore the relationship between memory span and reading speed in the inverse direction. In other words, future trials should assess the benefits, if there are any, of language memory span development in reading speed improvement.

Finally, while the experiment attested to the strong relationship between reading speed and memory span, it could not detect any evidence that reading speed improvement facilitates language accuracy. The memory span results revealed a minimal percentage of accuracy improvement among the participants, even for the treatment groups. While it could be argued that the measuring method might not be reliable, it is still necessary that further research be done to explore this intriguing relationship. An issue that emerged from the analysis was the seemingly contradictory findings related to accuracy in the memory span tests and in the texts that were included in the speed reading course. Whereas accuracy in the memory span tests was improved, comprehension in other types of texts outside the speed reading course was more significantly enhanced. A possible explanation may be that accuracy in comprehension of other types of texts somehow relates to receptive skills, while accuracy in memory span tests is more closely related to productive skills. It was thus possible that since speed improvement is largely associated with the receptive dimension of language skills, it could more strongly enhance accuracy within the same dimension but not accuracy in the other dimension of language skills. Again, this finding provides useful information for language teachers and learners, who should be aware that, while practice in one receptive skill may reinforce other receptive skills, productive skills might not simultaneously develop.

\section{Conclusion}

The results of the experiment have added to our understanding of the benefits of speed reading courses and made several contributions to the current literature on second language development. The evidence that speed reading courses bring various benefits to EFL learners and that comprehension and reading speed are not in a trade-off relationship may help teachers and learners to be more confident to use techniques and devices to promote reading speed.

The research found that reading speed improvement is accompanied by language memory span development. In other words, development in one aspect of language knowledge may facilitate development in other aspects of language knowledge. It can be speculated that the improvement in memory span will transfer to greater complexity in L2/FL, but this would need to be examined in further studies. Even though future research is warranted to confirm some intriguing issues, the findings of the experiment do expand previous research and have noteworthy implications for language syllabus designers, language teachers and language learners, especially those who are involved in reading skill courses.

\section{References}

Alessi, S., \& Dwyer, A. (2008). Vocabulary assistance before and during reading. Reading in a Foreign Language, 20(2), 246-263.

Bell, T. (2001). Extensive reading: Speed and comprehension. The Reading Matrix, 1(1), 1-13. 
Bismoko, J., \& Nation, I. S. P. (1972). Reading speed and transfer of training. Publikasi Ilmu Keguruan Sastra Seni, 2(2), 3-5.

Bowey, J. (2005). Predicting individual differences in learning to read. In M. Snowling \& C. Hulme (Eds.), The science of reading (pp. 155-172). Malden, MA: Blackwell.

Carver, R. P. (1992). Reading rate: Theory, research, and practical implications. Journal of Reading, 36(2), $84-95$.

Chang, A. C. S. (2010). The effect of a timed reading activity on EFL learners: Speed, comprehension, and perceptions. Reading in a Foreign Language, 22(2), 284-303.

Chung, M., \& Nation, P. (2006). The effect of a speed reading course. English Teaching, 64(4), 181-204.

Cramer, S. (1975). Increasing reading speed in English or in the national language? RELC Journal, 6, 19-25.

Daneman, M. \& Carpenter, P. A. (1980). Individual differences in working memory and reading. Journal of Verbal Learning and Verbal Behavior, 19, 450-466.

Das, J. P., \& Mishra, R. K. (1991). Relation between memory span, naming time, speech rate, and reading competence. The Journal of Experimental Education, 59(2), 129-139.

Fortkamp, M. B. M. (1999). Working memory capacity and aspects of L2 speech production. Communication and Cognition, 32, 259-296.

Fry, E. (1967). Reading faster. Cambridge: Cambridge Univerisity Press.

Fuchs, L., Fuchs, D., Hosp, M., \& Jenkins, J. (2001). Oral reading fluency as an indicator of reading competence: A theoretical, empirical, and historical analysis. Scientific Studies of Reading and Writing, 5, 239-256.

Harrington, M., \& Sawyer, M. (1992). L2 working memory capacity and L2 reading skill. Studies in Second Language Acquisition, 14, 25-38.

Harris, D. (1970). Report on an experimental group administered memory span test. TESOL Quarterly, 4(3), 203-213.

Hunter, M. J. M. (1975). The effect of speed reading and college reading/study skills instruction on grade point average. Colorado: University of Northern Colorado.

Just, M. A., \& Carpenter, P. A. (1992). A capacity theory of comprehension: Individual differences in working memory. Psychological Review, 99, 122-149.

Kormos, J., \& Sáfár, A. (2008). Phonological short-term memory, working memory and foreign language performance in intensive language learning. Bilingualism: Language and Cognition, 11, 261-271.

Kuhn, M., \& Stahl, S. (2003). Fluency: A review of development and remedial practices. Journal of Educational Psychology, 95(1), 1-21.

Lado, R. (1965). Memory span as a factor in second language learning. International Review of Applied Linguistics, 3, 123-129.

Levy, B., Abello, B., \& Kysynchuk, L. (1997). Transfer from word training to reading in context: Gains in reading fluency and comprehension. Learning Disability Quarterly, 20, 173-188.

Macalister, J. (2008). Effect of a speed reading course in an English as a second language environment. TESOLANZ Journal, 16, 23-32.

Macalister, J. (2010). Speed reading courses and their effect on reading authentic texts: A preliminary investigation. Reading in a Foreign Language, 22(1), 104-116.

Millett, S., Quinn, E., \& Nation, P. (2007). Asian and Pacific speed readings for ESL learners. Wellington: English Language Institute Ocasional Publication.

Nicholson, T., \& Tan, A. (1997). Flashcards revisited: Training poor readers to read words faster improves their comprehension of text. Journal of Educational Psychology, 89(2), 276-288.

Nicholson, T., \& Tan, A. (1999). Proficient word identification for comprehension. In G. B. Thomson \& T. Nicholson (Eds.), Learning to read: Beyond phonics and whole language (pp. 150-173). New York: Teachers College Press.

Perfetti, C., Landi, N., \& Oakhill, J. (2005). The acquisition of reading comprehension skill. In M. Snowling \& C. Hulme (Eds.), The science of reading (pp. 227-247). Malden, MA: Blackwell.

Quinn, E., \& Nation, I. S. P. (1974). Speed reading: A course for learners of English. Oxford: Oxford University Press.

Roberts, R., \& Gibson, E. (2002). Individual differences in sentence memory. Journal of Psycholinguistic Research, 31(6), 573-598.

Schmitt, N., Schmitt, D., \& Clapham, C. (2001). Developing and exploring the behaviour of two new versions of the vocabulary levels test. Language Testing, 18(1), 55-88.

Schwanenflugel, P. J., Meisinger, E. B., Wisenbaker, J. M., Kuhn, M. R., Strauss, G. P., \& Morris, R. D. (2006). Becoming a fluent and automatic reader in the early elementary school years. Reading Research Quarterly, 41(4), 496-522. 
Service, E. (1998). The effect of word length on immediate serial recall depends on phonological complexity, not articulatory duration. Quarterly Journal of Experimental Psychology, 51A, 283-304.

Seung, H.-K., \& Chapman, R. (2004). Sentence memory of individuals with Down's syndrome and typically developing children. Journal of Intellectual Disability Research, 8(2), 160-171.

Stanovich, K. E. (2000). Progress in understanding reading. New York: Guilford.

Weissheimer, J., \& Mailce, M. B. (2009). Individual differences in working memory capacity and the development of L2 speech production. Issues in Applied Linguistics, 17(2), 1-20.

Yuan, F., \& Ellis, R. (2003). The effects of pretask planning and online planning on fluency, complexity, and accuracy in L2 monologic oral production. Applied Linguistics, 24, 1-27. 